\title{
Meta-Ethnography and its Potential for Theory Building in Library and Information Science
}

\author{
Nancy Everhart, Melissa P. Johnston
}

\begin{abstract}
Meta-ethnography is an interpretive method that provides a way to synthesize the findings of two or more qualitative studies concerning a similar research question or topic. Going beyond the traditional literature review, which looks at individual studies, meta-ethnography facilitates generalizations through extracting concepts, metaphors, and themes. This paper provides a thorough description of the seven steps of meta-ethnography as defined by Noblit and Hare (1988). Implications for this method and the field of Library and Information Science (LIS), especially in the area of theory building, are discussed. Appropriate examples of actual and potential applications within LIS and related disciplines are given to illustrate the potential for the meta-ethnographic method.
\end{abstract}

\section{Introduction}

The discipline of Library and Information studies is principally defined as a social science, and ethnography is employed for social understanding (Bawden, 2012). Meta-ethnography, a method developed by George W. Noblit and R. Dwight Hare (1988), enables researchers to understand and synthesize the findings of two or more qualitative studies concerning a similar research question or topic. Mike Weed (2005) has described meta-ethnography as a form of meta-interpretation. Going beyond the traditional literature review, which looks at individual studies, meta-ethnography facilitates generalizations through extracting concepts, metaphors, and themes (Burns, 1989).

Meta-ethnography is interpretive rather than aggregative, with the goal being to “produce new interpretations of the primary study author's interpretations (e.g., themes, concepts or metaphors) of the research participants' experiences in published primary qualitative studies" (France et al., 2014, 4). Also, unique to

\section{Authors}

Nancy Everhart is a Professor at Florida State University

Email: nancy.everhart@cci.fsu.edu

Melissa P. Johnston is an Associate Professor at the University of West Georgia

Email: mjohnsto@westga.edu 
meta-ethnography is the systematic analysis process designed to preserve the context and meanings of the primary studies through utilizing translation, which is "the process through which data are synthesised - it involves continuously comparing the meaning of the concepts from all the primary studies to reach a full understanding of the issues" (France et al., 4). Noblit and Hare $(1988,28)$ described it as "making a whole into something more than the parts alone imply" or going beyond the findings of any individual study.

\section{Implications of the Method for Library and Information Science}

As qualitative research has been increasing over the past three decades, particularly in top-ranked Library and Information Science journals (e.g., Agosto et. al, 2007; Chu, 2015; Hider and Pymm, 2008), meta-ethnography can provide a useful method for synthesizing this research for new understandings. Some have noted that as a discipline we need to make better use of existing research evidence, instead of conducting yet more small-scale studies (Urquhart, 2011). Library and information science (LIS) has been criticized for a lack of dialogue, a tendency to develop new models - rather than test the transferability of existing models, confusion over the paradigms used, and using a narrow lens to examine a problem (Bates, 2007; Dervin, Reinhard, and Shen, 2006). Meta-ethnography, by reconceptualizing and synthesizing existing research, "compels us to acknowledge the uniqueness of individual cases, but also the uniqueness of collectives" (Urquhart, 2011, 38).

There have also been multiple calls for theory development in the field of LIS (e.g., Julien, Pecoskie, and Reed, 2011; Kim and Jeong, 2006; Kumasi, Charbonneau, and Walster, 2013; MeKechnie and Pettigrew, 2002; Pettigrew and McKechnie 2001). A theoretical foundation helps define a discipline and is necessary "for framing research problems, building arguments, and interpreting empirical results" (Pettigrew and McKetchnie, 2001, 62). Assembling the findings of multiple primary studies using a systematic process, such as meta-ethnography, can help generate comprehensive and generalizable theory. Wasif Afzal (2006, 23) argues that there has been an overuse of surveys and questionnaires in LIS, which are "snapshots of behavior that do not lead to a general theory". Metaethnography leads to an in-depth understanding of a particular phenomenon as it addresses problems from various dimensions across multiple studies. By exploring these dimensions, it could contribute to the theoretical foundations of our discipline (Afzal, 2006).

With meta-synthesis (a form of meta-ethnography) there is much more emphasis on compare and contrast, exploration of the theoretical assumptions and their implications and the quality of the research evidence is considered carefully. Above all, meta-synthesis is a rigorous approach to critique and analysis of the research evidence. Meta-synthesis may be used to identify the research gaps, to provide a deeper understanding of a problem area, with a systematic approach to producing explanations. The main benefit of meta-synthesis is that the 'whole' picture provided by meta-synthesis should be greater than the 'sum of the parts'. New knowledge - whether on theory, methodology, or data analysis and integration - should emerge.

(Urquhart, 2011, 37) 
It has been posited that since only the high quality data are analyzed in a metaethnography, it can lead to conclusions on the effectiveness of an intervention and the creation of new understandings (Bawden, 2012; Urquhart, 2011). This is an extremely valuable application of the method for LIS because "unfortunately, randomised controlled trials are not appropriate for answering many of the questions that arise in information behaviour" (Urquhart, 2011, 40).

Jonathan Lomas (as cited in Shelbe, 2016) pointed to the development of data repositories over a decade ago as a resource in extending synthesis approaches to incorporate viewpoints of a wider spectrum of stakeholders. The increase of university research repositories makes a wide range of unique historical, as well as original, research broadly available in LIS, which can function as sources for meta-ethnography studies.

Meta-ethnography also has implications for research teams. The method is richer when multiple researchers bring various perspectives to the process of reading, summarizing, and bridging summaries. This leads to resulting products that are logical, deductive rationalizations, sound conclusions, and to calls for further research (Doyle, 2003; Toye et al., 2014). Meta-ethnography extends borders by allowing researchers to communicate across fields, which is important in an interdisciplinary and multi-faceted field like LIS. Meacham $(1998,405)$ argues that today's educational issues and problems cannot be studied in an isolated and homogeneous manner; researchers from multiple disciplines need to be "brought together simultaneously". Norman Lincoln and Yvonna Denzin (2000) even suggest that researchers can enhance translations by including the voices of those researched to seek new interpretations. Additionally, when researchers enhance their translations with rich detail and the language of participants, they raise, not mute, the voices of those who are researched.

\section{Description of the Method}

Noblit and Hare (1988) provide a seven-step process for conducting a metaethnography: Getting Started; Reading the Studies; How are the Studies Related; Translating the Studies; Synthesizing Translations; and Expressing Synthesis (see Figure 1). This method begins with the research idea and takes the researcher through to expressing the findings. Each step is described in detail below. The steps are not necessarily discrete, but rather are part of an iterative research process (Toye et al., 2014). 


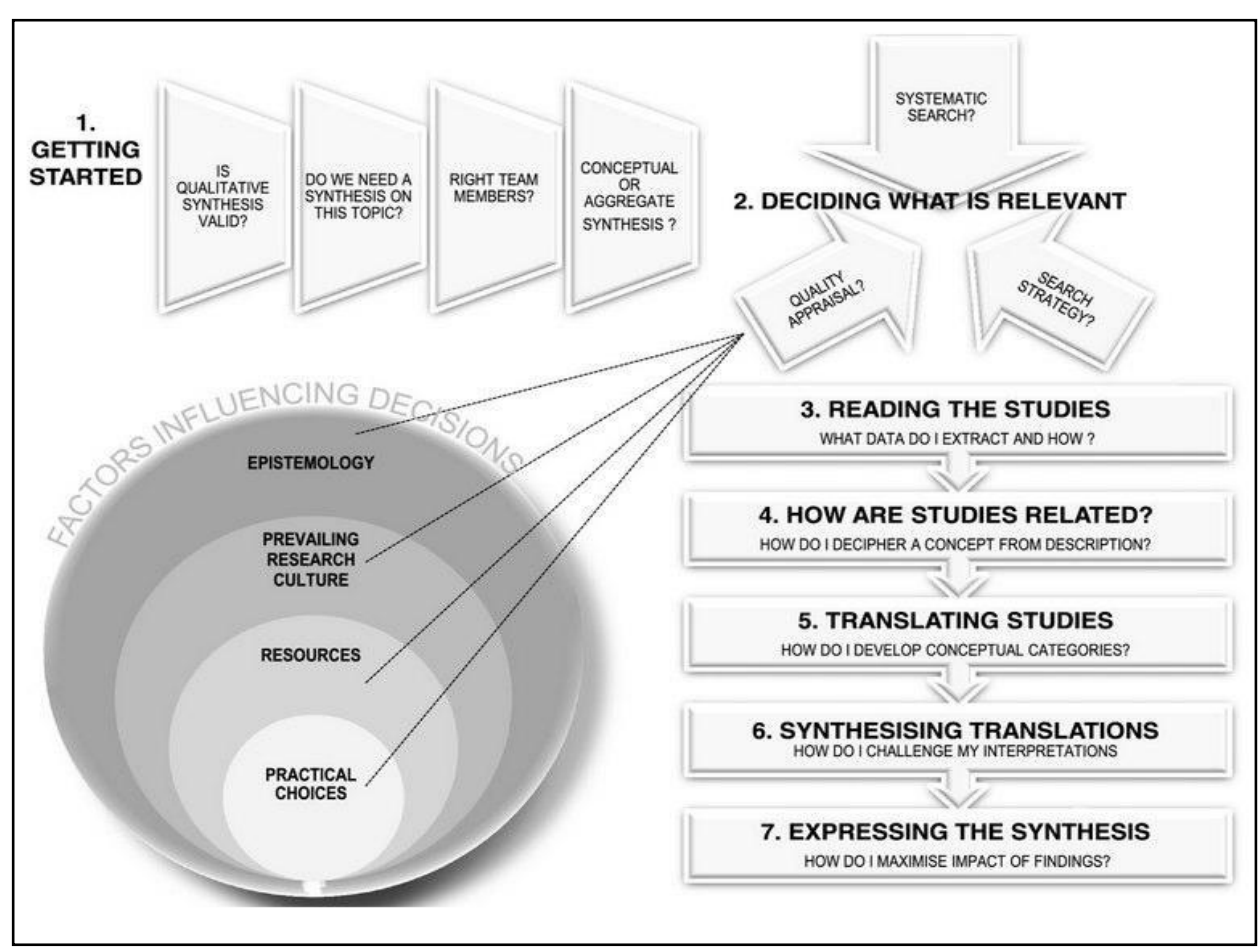

Figure 1: Stages of meta-ethnography (Toye et al., 2014).

\subsection{Step 1: Getting Started}

A meta-ethnography starts, like all inquiries, with an interest in some setting, topic, argument, issue, controversy or opportunity. This interest, for interpretivists, need not be overly specific. Often it starts simply from seeing what different qualitative researchers have to say about something and being concerned with how to compare their accounts

(Noblit and Hare, 1988, 3).

In this step it is important to consider if research synthesis fits the purpose of the inquiry, is synthesis of the topic needed, and what experience or knowledge do the researchers need (Toye et al., 2014).

\subsection{Step 2: Deciding What Is Relevant to the Initial Interest}

The scope of a meta-ethnographic study will often be more restricted than that of many narrative reviews, which is perfectly acceptable. In their 1988 guide, Noblit and Hare note that examining two to six studies is commonplace; metaethnography has no defined sampling procedure. Unlike meta-analysis, metaethnography does not attempt to summarize the entire body of available literature on a topic.

Meta-ethnography focuses on conceptual insight, and including too many studies might make conceptual analysis 'unwieldy' or make it difficult to maintain insight or sufficient familiarity

(Toye et al., 2014, 17). 
Researchers must focus on relevant studies by determining inclusion and exclusion criteria. Factors in deciding what studies are relevant involves knowing who the audience for the synthesis is, what is credible and interesting to them, what accounts are available to address the audience's interests, and what the researchers' interests are in the effort (Noblit and Hare, 1988).

Meta ethnography provides an "alternative to traditional aggregative methods of synthesis. It is a method that involves induction and interpretation of the studies...it aims to synthesise" (Britten et al., 2002, 2102). Yet, it is important that the interpretations of the original researcher are used, then the focus on meaning in context of the original study is retained. When researchers bring together many different interpretations, common themes and differences can be discovered and new interpretations can be built (Schreiber, Crooks, and Stern, 1997).

\subsection{Step 3: Reading the studies}

This step of meta-ethnography "involves thoroughly reading and rereading the studies to identify and describe the concepts. This requires extensive attention to the details in the accounts" (Noblit and Hare, 1988, 28). Yet, repeated reading continues throughout all phases of meta-ethnography, which allows for immersion in the data where new discoveries may emerge.

\subsection{Step 4: Determining How the Studies Are Related}

In the next phase the researcher determines the relationships between the different studies by looking across the different studies for common and recurring concepts. Noblit and Hare (1988) recommend creating a list of metaphors, phrases, ideas and/or concepts (and their relations), and juxtaposing them. There are many qualitative techniques that can be utilized for extracting concepts from the studies, such as memoing, coding, concept mapping, or diagramming. A common technique utilized in this step is to create a grid to see how the concepts relate to each other (Britten et al., 2002). Schütz's (1962) concept of first- and secondorder constructs is frequently used in meta-ethnography studies to extricate the data of meta-ethnography. First-order constructs are the everyday understandings of ordinary people and second-order constructs are the researcher's interpretations based on first-order constructs. The data of meta-ethnography are the secondorder constructs (Britten et al., 2002; Campbell et al., 2011; Toyle et al., 2014), which have been defined as discovering a "whole in a set of parts" by Noblit and Hare $(1988,16)$.

\subsection{Step 5: Translating the Studies into Each Other}

The next step in meta-ethnography is to determine how the second order constructs are related to each other by "sorting concepts into conceptual categories or 'piles' that shared meaning, thus translating studies into one another" (Toye et al., 2014, 31). A core element of meta-ethnography is translation, which means that the interpretations of studies are "translated into one another" (Noblit and Hare, 1988, 11). This translation requires the organization of the concepts by looking for similarities and difference between concepts and allows the researcher to understand and transfer concepts across multiple studies (Toye et al., 2014). This process of categorization using constant comparison is integral to qualitative 
research. Translations can either be "literal, word for word, translations or they can be idiomatic translations, in which the meaning of the text is preserved" (Britten et al., 2002, 210). It is this step of translating the studies that distinguishes meta-ethnography from more traditional methods of literature review (Britten $e t$ al., 2002).

\subsection{Step 6: Synthesizing Translations}

The next step in meta-ethnography is to make sense of the categories that emerged from the translations. It is in this step where the second-order constructs are further abstracted to develop third-order constructs or the researcher's interpretations of the original authors' interpretations are developed. Third order interpretations are derived from first and second order constructs reported in the primary studies (e.g., Atkins et al., 2008; Britten et al., 2002; Campbell et al., 2011). Third-order interpretations can be developed through synthesis with the aim of producing new interpretive context.

Synthesizing translations is an on-going process where findings are further abstracted to form a conceptual framework. Noblit and Hare (1988) suggest three ways of synthesizing translations:

Refutational syntheses (where findings contradict each other), reciprocal syntheses (where findings are directly comparable); findings are taken together and interpreted as a line of argument

(Noblit and Hare, 1988, 36)

Noblit and Hare $(1988,38)$ describe the process of translating findings into each other going something like, "one case [or study] is like another, except that ...". This synthesis of studies 1 and 2 would then be compared with study 3 in the same way. "Then the synthesis of [studies] 1, 2 and 3 would be compared with [study] 4, and so on until all the studies...had been translated into each other" (Campbell et al., 2011, 57). Another possible method of translation is refutational, where the studies are synthesized to see if any of the findings from the studies refuted each other. In the lines-of-argument synthesis, the studies are analysed thematically and this "involves a process of interpretation and conceptual advancement or third-order interpretations" (Campbell et al., 2011, 64). This type of synthesis says something about the whole based on studies of the parts. To conduct the synthesis, Noblit and Hare's recommend (1988) creating a list of metaphors, phrases, ideas, and/or concepts and their relationships (see Table 1). Fleshing out concepts and building these interpretations grounded in the findings of the separate studies is in line with the constant comparative method of grounded theory work (Watson et al., 2008).

Meta-ethnography "is an interpretive form of knowledge synthesis which aims to develop new conceptual understandings. This process is iterative and utilises an on-going form of knowledge production," (Toye et al., 2014, 35) therefore the constructed third-order interpretations can serve as theoretical underpinnings (Noblit and Hare, 1988). 


\subsection{Step 7: Expressing the Synthesis}

The final phase of meta-ethnography is expressing the synthesis or the reporting of the research findings (e.g., Britten et al., 2002; Campbell et al., 2011; France et al., 2014; Toye et al., 2014). Noblit and Hare (1988) emphasized the importance of "tailoring meta-ethnography reports to their intended audience" for effective dissemination to maximize impact (France et al., 2014, 51). The needs of the audience influence both the form and substance of the synthesis. Expressing the synthesis can take many forms, including publication, videos, infographics, or a conceptual model. Potential audiences may include researchers, practitioners, and policy makers (Britten et al., 2002).

\section{Meta-ethnography in Library and Information Science}

Laura Sheble (2016) recently echoed the thoughts of Hjørland (2001) from over a decade ago that research synthesis has been neglected in LIS literature. Exceptions include LIS communities associated with health and medical information, and the evidence-based practice movement. Meta-ethnography has firm roots in the medical field. It has been used to analyze a myriad of topics including musculoskeletal pain (Toye, et. al, 2014); psychological distress (Hoy, 2012); cervical cancer screening (Canty, 2016); and diabetes (Campbell et al., 2003) among many others. Sheble's (2016) study of the use of research synthesis methods revealed that approximately $80 \%$ of research synthesis publications appear in $20 \%$ of LIS titles. Sheble presents a detailed comparison of the differences in the steps in conducting research synthesis and a meta-ethnography, asserting that meta-ethnography is a more developed and interpretive approach. Keeping the defined differences in mind that differentiate research synthesis from meta-ethnography, the number of applications of meta-ethnography in LIS is virtually non-existent.

Although a few researchers have maintained that meta-analysis has the potential to make substantive contributions in LIS research (Afzal, 2006, Ankem, 2005; Bawden, 2012; Hjørland, 2001; Shelbe, 2016; Urquhart, 2011) there had not been a study in LIS that applied a meta-ethnographic approach as formulated by Noblit and Hare (1988) until recently (Everhart and Johnston, 2016). This research provides an example of how meta-ethnography can be applied for theory building in LIS. Meta-ethnography proved to be a rigorous and robust method to develop a conceptual model of school librarian leadership based on six studies that were relevant to the topic. The meta-ethnography method allowed for the identification of key concepts and the initial explanation of their interdependence. This resulted in five key propositions towards a theory of school librarian leadership which can be seen in Table 1.

The concepts and propositions derived from the meta-ethnographic exercise developed into a conceptual model (see Figure 3) to express the synthesis. Phase one of developing a conceptual model begins with conceptual development, which requires the formulation of "initial ideas in a way that depicts current, best, most informed understanding and explanation of the phenomenon, issue, or problem in the relevant world context"(Lynham, 2002, 231). 


\begin{tabular}{|c|c|c|c|c|}
\hline Focus of Studies & Concepts & $\begin{array}{l}\text { Second-Order } \\
\text { Interpretations }\end{array}$ & $\begin{array}{l}\text { Third-Order } \\
\text { Interpretations }\end{array}$ & Propositions \\
\hline $\begin{array}{l}\text { Leadership of } \\
\text { National Board } \\
\text { Certified School } \\
\text { Librarians } \\
\text { (Everhart, Mardis } \\
\text { and Johnston, } \\
\text { 2011) }\end{array}$ & $\begin{array}{l}\text { Relationships: } \\
\text { with peers, } \\
\text { teachers, students, } \\
\text { and principals } \\
\text { Communication: } \\
\text { within and } \\
\text { beyond the school } \\
\text { and the } \\
\text { professional } \\
\text { communities; face } \\
\text { to face and } \\
\text { electronic } \\
\\
\text { Confidence: } \\
\text { acquired via } \\
\text { education in } \\
\text { leadership skills } \\
\text { and strategies, } \\
\text { and via personal } \\
\text { use and expertise } \\
\text { with technology }\end{array}$ & $\begin{array}{l}\text { School librarians } \\
\text { value leadership } \\
\text { advice from those } \\
\text { inside the } \\
\text { profession rather } \\
\text { than those from } \\
\text { outside. }\end{array}$ & $\begin{array}{l}\text { School librarian } \\
\text { leadership is more } \\
\text { traditional than } \\
\text { transformational. } \\
\text { School librarian } \\
\text { leadership can be } \\
\text { taught to some } \\
\text { degree but } \\
\text { individual and } \\
\text { school } \\
\text { characteristics } \\
\text { influence the } \\
\text { extent that } \\
\text { leadership can be } \\
\text { exerted. }\end{array}$ & $\begin{array}{l}\text { Education can } \\
\text { provide a } \\
\text { leadership skill } \\
\text { set to bolster } \\
\text { confidence for } \\
\text { the growth of } \\
\text { school librarian } \\
\text { leadership. } \\
\text { Peers contribute } \\
\text { to school } \\
\text { librarian } \\
\text { leadership } \\
\text { growth. } \\
\text { School librarian } \\
\text { leadership growth } \\
\text { requires a } \\
\text { specific mind-set. } \\
\text { School librarian } \\
\text { leadership } \\
\text { engagement } \\
\text { follows } \\
\text { traditional } \\
\text { leadership } \\
\text { patterns and is } \\
\text { resistant to forms } \\
\text { of leadership that } \\
\text { require taking } \\
\text { risks. }\end{array}$ \\
\hline
\end{tabular}

Table 1: Results of a Meta-Ethnographic Study of School Librarian Leadership. 
The output of this phase is an explicit, informed, conceptual framework that often takes the form of a model and/or metaphor that is developed from the theorist's knowledge of and experience with the phenomenon, issue, or problem concerned.

(Lynham, 2002, 232).

The output for this first phase of theory building is a research-informed conceptual model (Lynham, 2002). Our model is based on flexible conceptual terms rather than rigid theoretical variables and causal relations, and can, therefore, be modified with the evolution of school librarian leadership or as a result of new research. Our Conceptual Model of School Librarian Leadership aims to help educators understand the phenomenon of school librarian leadership rather than to predict it (Everhart and Johnston, 2016).

\section{Conclusion}

The need for theoretical foundations for research in the Library and Information Science (LIS) field is well documented (Grover and Glazier, 1986; Hjørland, 1998; Julien and Duggan, 2000; Julien et al., 2011; Leckie, Given, and Buschman, 2010; MeKechnie and Pettigrew, 2002; Pettigrew and McKechnie, 2001). Theory is "an important element for establishing the identity of LIS" (Kim and Jeong, 2006, 549) and yet there has been little attention paid to theory in the literature of the field and even a decline in theory use and development (Julien and O'Brien 2014; Kim and Jeong, 2006). This decline in theory development may represent a trend in LIS research to utilize "existing theory rather than to generate new theories" (Kim and Jeong, 2006, 559).

Our utilization of meta-ethnography for theory building in LIS provides a model and proof in concept for other researchers. Use of synthesis methods such as meta-ethnography "is an important development for library and information science researchers and practitioners because it has affected how researchers in other fields interact with literature, data, and information infrastructures" (Sheble, 2016, 1990). Opportunities arise from "undiscovered public knowledge"

(Swanson, 1986, 104) and the ability to synthesize across research studies for the purpose of contributing to theory development (Glaser and Strauss, 1971; Grover and Glazier, 1986).

\section{References}

Afzal, W. (2006) An argument for the increased use of qualitative research in LIS, Emporia State Research Studies, 43(1), 22-25.

Agosto, D., Shanshan, M. and Yen, B. (2007) Qualitative trends in library \& information science (LIS) research, URL: http://hdl.handle.net/1860/1588 [accessed 13.1.17].

Ankem, K. (2005) Approaches to meta-analysis: A guide for LIS researchers, Library \& Information Science Research, 27(2), 164-176. 
Atkins, S., Lewin, S., Smith, H., Engel, M., Fretheim, A., and Volmink, J. (2008) BMC Medical Research Methodology, 8(21). URL:

http://bmcmedresmethodol.biomedcentral.com/ articles/10.1186/1471-2288-8-21 [accessed 13.1.17].

Bates, M. J. (2007) What is browsing-really? A model drawing from behavioural science research, Information Research, 12(4). URL: http://InformationR.net/ ir/12-4/paper330.html [accessed 13.1.17].

Bawden, D. (2012). On the gaining of understanding: syntheses, themes and information analysis, Library and Information Research, 36(112), 147-162.

Britten, N., Campbell, R., Pope, C., Donovan, Morgan, M., and Pill, R. (2002) Using meta-ethnography to synthesize qualitative research: A worked example, Journal of Health Services Research \& Policy, 7(4), 209 -15.

Burns, N. (1989). Standards for qualitative research, Nursing Science Quarterly, 2(1), 44-52.

Campbell, R., Pound, P., Morgan, M., Daker-White, G., Britten N, Pill,R., Donovan, J. (2011) Evaluating meta-ethnography: Systematic analysis and synthesis of qualitative research, Health Technology Assessment, 15(43).

Retrieved from http://www.ncbi.nlm.nih.gov/ pubmed/22176717

Campbell, R., Pound, P., Pope, C., Britten, N., Pill, R., Morgan, M., and Donovan, J. (2003) Evaluating meta-ethnography: a synthesis of qualitative research on lay experiences of diabetes and diabetes care, Social Science \& Medicine, 56(4), 671684.

Canty, L. (2016) Cervical cancer screening among black women: A metaethnography, Nursing Research, 65(2), E40-E41.

Chu, H. 2015 Research methods in library and information science: A content analysis, Library and Information Science Research, 37, 36-41.

Dervin, B., Reinhard, C. D. and Shen, F. C. (2006) Beyond communication: research as communicating. Making user and audience studies matter, Information Research, 12(1). URL: http://InformationR.net/ir/12-1/paper287.html [accessed 13.1.17].

Doyle, L. (2003) Synthesis through meta-ethnography: paradoxes, enhancements, and possibilities, Qualitative Research, 3(3), 321-344.

Everhart, N., and Dresang, E. T. (2007) Integrating research results and national board certification standards into a leadership curriculum for school library media specialists, Journal for Education in Library and Information Science, 48(4), 271283.

Everhart, N, and Johnston, M. P. (2016) A proposed theory of school librarian leadership: A meta-ethnographic approach, School Library Research, 19. URL: http://www.ala.org/aasl/slr [accessed 13.1.17].

Everhart, N., Mardis, M., and Johnston, M. P. (2011). National board certified school librarians' leadership in technology integration: Results of a national 
survey. School Library Media Research, 14(1). URL: http://www.ala.org/aasl/slr [accessed 13.1.17].

France, E. F., Ring, N., Thomas, R., Noyes, J., Maxwell, M., and Jepson, R. (2014) A methodological systematic review of what's wrong with metaethnography reporting, BMC Medical Research Methodology, 14(119). URL: https://bmcmedresmethodol.biomedcentral.com/articles/10.1186/1471-2288-14119 [accessed 13.1.17].

Glaser, B. G., and Strauss, A. L. (1971) Status passage: A formal theory. Chicago, IL: Aldine.

Grover, R., and Glazier, J. (1986) A conceptual framework for theory building in library and information science, Library and Information Science Research, 8(3), 227-42.

Hider, P., and Pymm, B. (2008) Empirical research methods reported in high profile LIS journals, Library and Information Science Research, 30, 108-114.

Hjørland, B. (1998) Theory and metatheory of information science: A new interpretation, Journal of Documentation, 54(5), 606-21.

Hjørland, B. (2001) Why is meta-analysis neglected by information scientists? Journal of the American Society for Information Science and Technology, 52(13), 1193-1194.

Hoy, S. (2012) Beyond men behaving badly: A meta-ethnography of men's perspectives on psychological distress and help seeking, International Journal of Men's Health, 11(3), 202-226.

Johnston, M. P. (2012) School librarians as technology integration leaders: Enablers and barriers to leadership enactment, School Library Research, 15(1). URL: http://www.ala.org/aasl/slr [accessed 13.1.17].

Julien, H., and Duggan, L. J. (2000) A longitudinal analysis of the information needs and uses Literature, Library and Information Science Research, 22(3), 291309.

Julien, H., and O'Brien, M. (2014) Information behavior research: Where have we been, where are we going? Canadian Journal of Information and Library Science, 38(4), 239-250

Julien, H., Pecoskie, J. and Reed, K. (2011) Trends in information behavior research, 1999-2008: A content analysis, Library \& Information Science Research, 33(1), 19-24.

Kang, J. H. (2015) The leadership role of school librarians in the adoption of digital textbooks: Evaluating school librarians' stages of concern in Florida and South Korea. Doctoral dissertation, Florida State University, Tallahassee.

Kim, S., and Jeong, D. Y. (2006) An analysis of the development and use of theory in library and information science research, Library and Information Science Research, 28(4), 548-562. 
Kumasi, K. D., Charbonneau, D. H., and Walster, D. (2013) Theory talk in the library science scholarly literature: An exploratory analysis, Library \& Information Science Research, 35(3), 175-180.

Leckie, G. J., Given, L. M., and Buschman, J. E. (eds). (2010) Critical theory for library and information science: Exploring the social from across the disciplines. Santa Barbara, CA: Libraries Unlimited.

Lincoln, Y. S., and Denzin, N. K. (2000) The seventh moment: Out of the past. In Denzin, N. K. and Y. S. Lincoln (eds.) Handbook of qualitative research (pp. 1047-65). Thousand Oaks, CA: Sage.

Lynham, S. A. (2002). General method of theory building in applied disciplines, Advances in Developing Human Resources 4 (3), 221-241.

Mardis, M., \& Everhart, N. (2014) Stakeholders as researchers: A multiple case study of using cooperative inquiry to develop and document the formative leadership experiences of new school library professionals. Library and Information Science Research, 36(1), 3-15.

McKechnie, L., and Pettigrew, K. E. (2002) Surveying the use of theory in library and information science research: A disciplinary perspective, Library Trends, 50(3), 406-417

Meacham, S. J. (1998) Threads of a new language: A Response to Eisenhart's on the subject of interpretive review, Review of Educational Research, 68(4), 401408.

Noblit, G. W., and Hare, R. D. (1988) Meta-ethnography: Synthesizing qualitative studies. Newbury Park, CA: Sage.

Pettigrew, K. E., and McKechnie, L. (2001) The use of theory in information science research. Journal of the American Society for Information Science and Technology, 52(1), 62-73.

Schreiber, R., Crooks, D., and Stern, P. N. (1997) Qualitative meta-analysis. In Morse, J. M. (ed.), Completing a qualitative project: Details and dialogue (pp. 311-326). Thousand Oaks, CA: Sage.

Schütz A. ( 1962). Collected papers 1. The Hague: Martinus Nijhoff.

Sheble, L. (2016) Research synthesis methods and library and information science: Shared problems, limited diffusion, Journal of the Association for Information Science and Technology, 67(8), 1990-2008.

Smith, D. (2009) Self Perceptions of Leadership Potential: A Study of TeacherLeaders Educated to be School Library Media Specialists Who Lead. Doctoral dissertation, Florida State University, Tallahassee.

Swanson, D. R. (1986) Undiscovered public knowledge, Library Quarterly, 56(2), 103-118.

Toye, F., Seers, K. Allcock, N., Briggs, M. Carr, E., and Barker, K. (2014) Metaethnography 25 years on: Challenges and insights for synthesising a larger number of quantitative studies, BMC Medical Research Methodology, 14(80). 
URL: https://bmcmedresmethodol.biomedcentral.com/articles/10.1186/14712288-14-80 [accessed 13.1.17].

Urquhart, C. (2011) Meta-synthesis of research on information seeking behavior, Information Research, 16(1). URL: http://www.informationr.net/ir/161/paper455.html [accessed 13.1.17].

Watson, R., et al., eds. (2008). Nursing research: Designs and methods. Edinburgh, Scotland: Elsevier.

Weed, M. (2005) Meta interpretation: A method for the interpretative synthesis of qualitative research, Qualitative Social Research, 6(1). URL: www.qualitativeresearch.net/index.php/fqs/article/view/508/1096 [accessed 13.1.17].

\section{Open access and copyright}

Library and Information Research is an open access journal. A freely available copy of this paper may be downloaded from the journal's website:

http://www.lirgjournal.org.uk/

Copyright and associated moral rights in works published in Library and Information Research are retained by the author(s) but this paper may be used freely, with proper attribution, in educational and other non-commercial settings. 